\title{
Changes in quantitative EEG and blood flow velocity due to standardized hyperventilation; a model of transient ischaemia in young human subjects
}

\author{
V. Kraaier, A.C. Van Huffelen and G.H. Wieneke \\ Dept. of Clinical Neurophysiology, University Hospital Utrecht, Utrecht (The Netherlands)
}

(Accepted for publication: 15 March 1988)

\begin{abstract}
Summary A standardized hyperventilation (HV) procedure has been developed in which the end-tidal pCO $\mathrm{CO}_{2}$ was decreased to 2 $\mathrm{kp}_{\mathrm{a}}$. In 24 young male subjects blood flow velocity and $\mathrm{qEEG}$ were studied before, during and after HV. This standardized hyperventilation procedure gave rise to a decrease in blood flow velocity to $40 \%$ of baseline value and highly significant qEEG changes in 3 derivations. Both relative and absolute band power estimates showed an increase in slow activity and a decrease in alpha and beta activity. The use of subtraction spectra led to a more precise and detailed presentation of these changes than the use of classical qEEG parameters. These changes were reproducible after 1 week. The effects found in the presented model of HV-induced ischaemia appeared to be twice as large as those found in a model of hypobaric hypoxia. The present model might be used to test the efficacy of anti-ischaemic drugs in young human subjects.
\end{abstract}

Key words: qEEG; Transient ischaemia model; Normal subjects

Of all physical activation methods in use for the provocation of EEG changes, hyperventilation (HV) is perhaps the most commonly used. HV gives rise to a decrease in arterial $\mathrm{pCO}_{2}$, leading to vasoconstriction of the arteriolar channels and as a consequence a decrease in cerebral blood flow (CBF) (Kety and Schmidt 1948; Yamaguchi 1979). Recently a reduction in blood flow velocity (BFV) in the large cerebral vessels has been demonstrated using the transcranial Doppler (TCD) technique (Markwalder et al. 1984). Despite ample administration of oxygen, the $\mathrm{HV}$-induced flow reduction may lead to cerebral tissue hypoxia (Clark et al. 1958; Sugioka and Davis 1960; Kennealy et al. 1980) and to cerebral tissue lactic acidosis (Plum and Posner 1967; Kogure et al.

Correspondence to: V. Kraaier, Dept. of Clinical Neurophysiology, University Hospital Utrecht, Utrecht (The Netherlands).
1975; Luyten et al. 1987). Thus, HV may be considered as an experimental method of inducing transient ischaemic hypoxia. The fact that similar EEG changes are observed in normal subjects during $\mathrm{HV}$ and in patients with cerebral ischaemia gives further support to this conception.

Aim of this study was to establish a model of reversible $\mathrm{HV}$-induced ischaemic hypoxia. This was achieved by standardizing the HV procedure by means of capnographic monitoring, which resulted in reproducible changes in BFV and quantitative EEG (qEEG). In this model several qEEG parameters were studied in 3 derivations for both relative and absolute power densities. Furthermore, a comparison was made between spectral changes in this HV model and in the earlier described hypobaric hypoxia model (Kraaier et al. 1988).

Since the effect of $\mathrm{HV}$ in the EEG decreases with age (Yamaguchi et al. 1979), only young subjects (age 20-25 years) were studied. 


\section{Subjects and methods}

Subjects

Twenty-four healthy, drug-free male students, between 20 and 25 years of age (mean age 22.2; S.D. 2.0) were studied. Prior to the study, each subject signed a consent form. Extensive physical examination, including lung function tests, laboratory examination, ECG and EEG recording, was normal in all subjects. Smoking and alcohol intake were prohibited for at least 3 days before the test.

To avoid hypoglycaemia, all measurements were conducted within $2 \mathrm{~h}$ after a meal. The subject was comfortably lying on a stretcher, in a semi-supine position $\left(30^{\circ}\right)$, with eyes closed.

\section{Instrumentation}

$E E G$. Silver/silver chloride electrodes were attached to the skin with collodion. The following 3 derivations, based on the international 10/20 system, were selected: F4-C4, T4-T6 and P4-O2. Only right-sided derivations were used to permit simultaneous transcranial Doppler sonography on the left side. The EEG recording was performed using a 21-channel encephalograph with a bandwidth $0.26-30 \mathrm{~Hz}(-3 \mathrm{~dB})$. Artifacts due to eye blinks, movement or muscle activity were reduced to a minimum by proper instruction of the subjects. Moreover, rejection of $2.5 \mathrm{sec}$ epochs contaminated by artifacts could be accomplished on line by the technician. At a sampling frequency of $100 \mathrm{~Hz}$ signals were directly fed into the computer for spectral analysis (frequency range 0.7-24.1 $\mathrm{Hz}$ ). An analysis time of $102.4 \mathrm{sec}$ (20 epochs of $5.12 \mathrm{sec})$ constituted the baseline spectrum, whereas an analysis time of $51.2 \mathrm{sec}$ (10 epochs of $5.12 \mathrm{sec}$ ) constituted the spectra during and after $\mathrm{HV}$. Effective frequency resolution was $0.59 \mathrm{~Hz}$.

Capnography. An infra-red gas analyser was used for capnographic control. Continuous sampling of gas from a mouthpiece was accomplished at a flow rate of $500 \mathrm{ml} / \mathrm{min}$ through a side tube of $140 \mathrm{~cm}$ length. The nose was closed with a noseclip.

Transcranial Doppler sonography. BFV recording was performed using an EME TC 2-64 apparatus. Mean flow velocity from the left middle cerebral artery (MCA) was measured, accord-

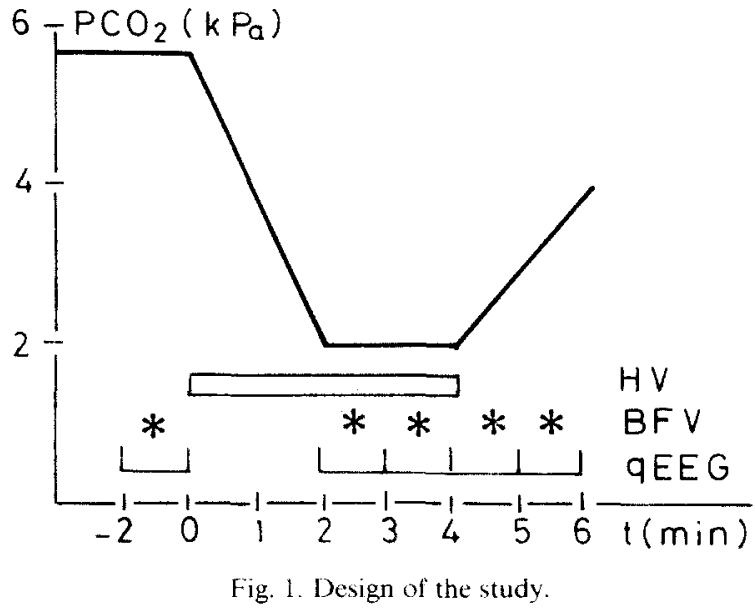

ing to the method described by Aaslid et al. (1982). The part of the MCA giving the highest Doppler velocity was chosen for recording of the BFV.

$E C G$. A continuous 2 lead ECG was recorded together with the EEG signals to monitor the heart rate and possible ischaemic changes.

\section{Methods}

The design of the study is indicated in Fig. 1.

(a) Baseline. First the subject breathed at his normal speed and depth through the mouthpiece for $10 \mathrm{~min}$ while the capnogram was recorded. The volunteer closed his eyes and a $102.4 \mathrm{sec}$ EEG sample was taken for spectral analysis (baseline spectrum). BFV was recorded simultaneously. Blood pressure and pulse rate (from ECG) were measured as well.

(b) $H V$ provocation. After baseline recording the subject started a 4 min $\mathrm{HV}$ period with eyes closed. The subject was instructed to increase the frequency of ventilation to $30 / \mathrm{min}$, as indicated by a metronome. The depth of breathing was gradually increased to achieve within $2 \mathrm{~min}$ an end-tidal $\mathrm{pCO}_{2}$ level of $2.0 \pm 0.1 \mathrm{kp}_{\mathrm{a}}(=14.3-15.8$ torr). Instructions for appropriate ventilation depth were given to the subject by one of the authors (VK). Two and $3 \mathrm{~min}$ after starting $\mathrm{HV}$ $51.2 \mathrm{sec}$ qEEG samples were taken (HV spectra), together with $\mathrm{BFV}$ recording. Blood pressure and pulse rate were measured again.

(c) Recovery. The subject was asked to breath normally with his eyes still closed and in the first 
and second minutes after $\mathrm{HV}$ two $51.2 \mathrm{sec}$ qEEG samples were taken (recovery spectra).

\section{Reproducibility}

Twelve subjects (mean age $22.4 ;$ S.D. 2.3) repeated the procedure after a $1 \mathrm{~h}$ interval. The 12 other subjects (mean age 22.0; S.D. 1.7) repeated the procedure after 1 week. All experiments took place at the same time of the day (5.00-7.00 p.m.).

\section{TABLE I}

Spectral parameters and standard parameters used in this study.

\section{Spectral parameters}

lpd 1-lpd 20

lpd 21-lpd 30

\begin{tabular}{|c|c|}
\hline Total power & $\begin{array}{l}\text { Total power of the } 0.7-24.1 \text { band } \\
\text { in } \mu \mathrm{V}^{2} \text {. }\end{array}$ \\
\hline Rel p delta 1 & $\begin{array}{l}\text { Relative linear power in the delta } \\
1 \text { band }(0.7-2.4 \mathrm{~Hz}) \text { in } \% \text {. }\end{array}$ \\
\hline Rel p delta 2 & $\begin{array}{l}\text { Relative linear power in the delta } \\
2 \text { band }(2.4-4.2 \mathrm{~Hz}) \text { in } \% \text {. }\end{array}$ \\
\hline Rel p theta & $\begin{array}{l}\text { Relative linear power in the theta } \\
1 \text { band }(4.2-7.7 \mathrm{~Hz}) \text { in } \% \text {. }\end{array}$ \\
\hline Rel p alpha 1 & $\begin{array}{l}\text { Relative linear power in the alpha } \\
1 \text { band }(7.7-10.1 \mathrm{~Hz}) \text { in } \% .\end{array}$ \\
\hline Rel p alpha 2 & $\begin{array}{l}\text { Relative linear power in the alpha } \\
2 \text { band }(10.1-12.4 \mathrm{~Hz}) \text { in } \% .\end{array}$ \\
\hline Rel p beta 1 & $\begin{array}{l}\text { Relative linear power in the beta } \\
1 \text { band }(12.4-18.3 \mathrm{~Hz}) \text { in } \% .\end{array}$ \\
\hline Rel p beta 2 & $\begin{array}{l}\text { Relative linear power in the beta } \\
2 \text { band }(18.3-24.1 \mathrm{~Hz}) \text {. }\end{array}$ \\
\hline $\begin{array}{l}\text { Mean freq. tot. } \\
\text { spectrum }\end{array}$ & $\begin{array}{l}\text { Mean frequency of the total band } \\
(0.7-24.1 \mathrm{~Hz}) \text { in } \mathrm{Hz} \text {. }\end{array}$ \\
\hline $\begin{array}{l}\text { Mean freq. alpha } \\
\text { band }\end{array}$ & $\begin{array}{l}\text { Mean frequency of the alpha band } \\
(7.7-12.4 \mathrm{~Hz}) \text { in } \mathrm{Hz} \text {. }\end{array}$ \\
\hline $\begin{array}{l}\text { Hjorth's mob. } \\
\text { Hjorth's comp. }\end{array}$ & $\begin{array}{l}\text { Hjorth's mobility. } \\
\text { Hjorth's complexity. }\end{array}$ \\
\hline
\end{tabular}

\section{qEEG parameters}

Based on previous investigations and data from literature a number of parameters, concerning both spectral frequencies, power densities and Hjorth parameters were selected for evaluation (Keskimäki et al. 1980; Wieneke et al. 1980; Van Huffelen et al. 1984; Kennealy et al. 1986; Kraaier et al. 1988). Because it was unknown whether qEEG changes would adhere to the fixed boundaries of the 'classical' delta, theta, alpha and beta bands subtraction spectra were studied in addition (Kraaier et al. 1988). Subtraction spectra consisted of the logarithmic power density differences between two spectra from the same subject during different conditions (Table I). Within each subject, the spectrum recorded immediately before HV (baseline spectrum) was subtracted from the spectrum recorded during $\mathrm{HV}$ ( $\mathrm{HV}$ spectrum), in order to study spectral changes due to HV. Furthermore, baseline spectrum was subtracted from the spectrum recorded after cessation of hyperventilation (recovery spectrum), in order to study the spectral changes after cessation of hyperventilation. For the subtraction spectra both absolute power densities and relative power densities (i.e., the $\log$ power density minus the mean log power density in the 1.3-22.9 $\mathrm{Hz}$ range) were calculated.

\section{Statistics}

Statistics were performed on qEEG and BFV, using the Wilcoxon matched-pairs ranked signs test. As a measure of the statistical significance for an effect, the mean divided by the standard deviation among the subjects was calculated.

\section{Results}

\section{(I) Circulatory changes}

Pulse and blood pressure. During standardized HV there was no change in systolic or diastolic pressure. There was a mean increase in pulse rate to $158 \%$ of the baseline value (Table II).

Transcranial Doppler sonography. During standardized HV there was a mean decrease to $40 \%$ of the baseline value (Table II). 


\section{TABLE II}

Means (standard deviations) of physiological data before, during and 2 min after standardized HV (recovery). $\mathrm{N}=24$.

\begin{tabular}{lrrrr}
\hline & Baseline & \multicolumn{2}{c}{ 4 min HV } & \multicolumn{2}{c}{ Recovery } \\
\hline Pulse (rate/min) & $67(7)$ & $111(21)$ & $74(6)$ \\
Systolic pressure (torr) & $135(10)$ & $137(9)$ & $135(11)$ \\
Diastolic pressure (torr) & $90(6)$ & $90(6)$ & $90(5)$ \\
BFV (cm/sec) & $72(12)$ & $29(3)$ & $50(9)$ \\
\hline
\end{tabular}

\section{(II) EEG changes}

(1) The effect of standardized HV on EEG subtraction spectra

(a) Subtraction spectra of relative log power density. During standardized $\mathrm{HV}$ there was a relative increase in slow activity $(1.3-7.7 \mathrm{~Hz})$ and a relative decrease in both alpha $(8.3-11.8 \mathrm{~Hz})$ and beta activity (15.9-22.9 Hz) (Fig. 2, i.e., 4th min of HV). The spectral changes for all 3 derivations were highly significant. Differences between the 3 derivations were rather small, but statistically significant. These consisted of:

Increase in slow activity. The increase in slow activity in the $0.7-2.4 \mathrm{~Hz}$ range in derivations F4-C4 and T4-T6 appeared to be less than in P4-O2 $(P<0.01)$. This might be explained by the presence of some slow eye movement artifacts in the baseline EEG, leading to an increase in slow activity in the baseline spectra. As a consequence, the increase in slow activity in the subtraction spectra is reduced.

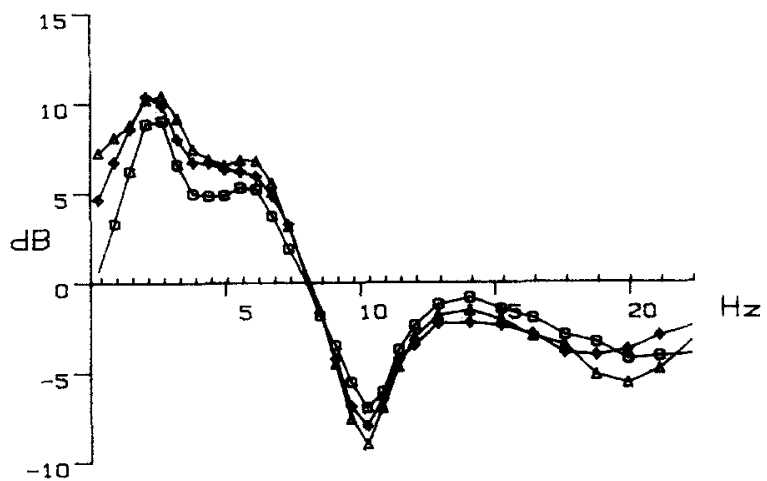

Fig. 2. Subtraction spectra of relative log power density during standardized $\mathrm{HV}$ for 3 derivations. $\mathrm{N}=24$. Symbols indicate a significant difference $(P<0.05) ; \square$ : F4-C4; $\triangle:$ P4-O2; $\diamond$ : T4-T6.

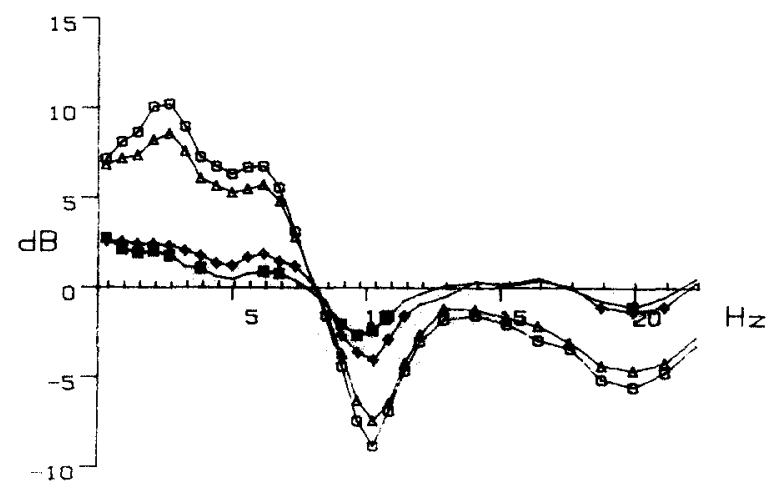

Fig. 3. Subtraction spectra of relative $\log$ power density during 3 th and 4th min of standardized $\mathrm{HV}$ and during 1 st and 2nd min after cessation of standardized HV. Derivation P4-O2. Symbols indicate a significant difference $(P<0.05) ; \triangle$ : 3th min of $\mathrm{HV} ; \square: 4$ th min of $\mathrm{HV} ; \diamond: 1$ min after $\mathrm{HV} ; \otimes ; 2$ min after HV.

Decrease in alpha activity. The decrease in alpha activity was most prominent in $\mathrm{P} 4-\mathrm{O} 2$, but not statistically different from the other derivations $(P>0.10)$.

Decrease in beta activity. Muscle artifacts, giving rise to an increase of power density in the beta range, were found in all derivations, but least in P4-O2. The differences were significant $(P<0.01)$ above $19.4 \mathrm{~Hz}$. On the other hand, in the posterior derivations harmonics of the alpha rhythm may contribute to an increase of power density in the beta range. For P4-O2 a moderate correlation of 0.5-0.6 between the power densities at alpha frequency and higher harmonics was found. These two effects lead to opposite consequences in the subtraction spectra. The net result of decrease in beta activity shows the relatively minor contribution of muscle artifacts.

The HV-induced EEG effects during the 4th min of $\mathrm{HV}$ were larger than those during the $3 \mathrm{rd}$ min (Fig. 3). These differences were statistically significant $(P<0.05)$ in the $1.3-6.0 \mathrm{~Hz}$ range and in the $8.9-22.9 \mathrm{~Hz}$ range.

In the recovery spectra there were still small, but significant, effects in the subtraction spectra, i.e., an increase in slow activity $(1.3-7.7 \mathrm{~Hz})$ and a decrease in alpha activity $(8.3-11.8 \mathrm{~Hz}$ ) (Fig. 3). In the $2.4-8.9 \mathrm{~Hz}$ range the changes in the 2 nd min after $\mathrm{HV}$ were significantly less in comparison 
TABLE III

Mean differences of standard parameters during $\mathrm{HV}\left(\mathrm{pCO}_{2}=2.0 \mathrm{kp}_{\mathrm{a}} ; 4\right.$ min $\left.\mathrm{HV}\right) . \mathrm{N}=24$. In brackets mean divided by standard deviations. $A l l$ values are significant with $P<0.001$, except the values followed by $*(0.001<P<0.01)$ or $* *(0.01<P<0.05)$.

\begin{tabular}{|c|c|c|c|}
\hline & $\mathrm{P} 4-\mathrm{O} 2$ & T4-T6 & F4-C4 \\
\hline Tot pow. $\left(\mu V^{2}\right)$ & $12.62 \quad(0.61)$ & $(1.26)$ & $(0.52)$ \\
\hline Rel p delta $1(\mathscr{B})$ & $(2.51)$ & $(2.32)$ & $14.58 *$ \\
\hline Rel p delta $2(\%)$ & $(2.58)$ & $(2.08)$ & $(0.99)$ \\
\hline Rel p theta (\%) & $(0.90)$ & $5.50 *(0.64)$ & $1.96 * *(0.24)$ \\
\hline Rel p alpha $1(\%)$ & $-24.02(-1.52)$ & $-18.86 \quad(-1.35)$ & $-8.77 \quad(-1.84)$ \\
\hline Rel p alpha $2(\%)$ & $-24.30(-1.40)$ & $-17.66 \quad(-1.35)$ & -11.36 \\
\hline Rel p beta $1(\%)$ & $-5.36(-1.69)$ & $-7.91 \quad(-1.44)$ & $(-1.29)$ \\
\hline Rel p beta $2(\%)$ & $-4.80(-1.61)$ & $-8.59 \quad(-0.82)$ & $(-1.45)$ \\
\hline mean freq. tot. spec. $(\mathrm{Hz})$ & $-5.26(-4.13)$ & $-5.47 \quad(-2.69)$ & $(-1.66)$ \\
\hline mean freq. alpha band $(\mathrm{Hz})$ & $-0.46(-0.95)$ & $-0.52 \quad(-1.07)$ & $(-1.13)$ \\
\hline Hjorth's mob. & $-5.17(-3.91)$ & $-5.17 \quad(-2.25)$ & $-2.55 \quad(-1.26)$ \\
\hline Hjorth's comp. & $1.53 * *(0.46)$ & $2.04 *(0.64)$ & $-2.37 * \quad(0.77)$ \\
\hline
\end{tabular}

with data from the preceding minute. Thus, when studying relative $\log$ power densities, the derivation P4-O2 should be preferred because of its largest statistical significance and least contamination with artifacts.

(b) Subtraction spectra of absolute log power density. Fig. 4 shows that the shape of the subtraction spectra of absolute log power density is not different from that of the relative power. The rise of the curves by about $1.5-5 \mathrm{~dB}$ is explained by the fact that the mean $\log$ power density, which appears to increase during the HV period, is no longer subtracted from the power density values. It now becomes clear that in the derivation F4-C4 not a decrease but an increase in slow beta activity

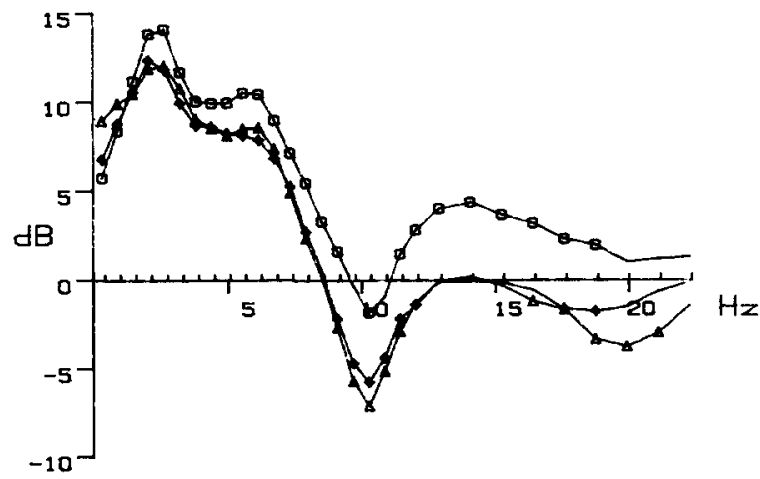

Fig. 4. Subtraction spectra of absolute log density during standardized $\mathrm{HV}$ for 3 derivations. $\mathrm{N}=24$. Symbols indicate a significant difference $(P<0.05)$.
(12.4-14.8 Hz) occurs during HV. This cannot be explained by the presence of muscle artifacts, which lead to faster beta activity. Furthermore, the subtraction spectra of absolute power density show that the decrease in alpha activity in the derivation P4-O2 and T4-T6 is a real decrease. It also becomes apparent that the normalization of the spectrum of the derivation F4-C4 results in an alpha decrease which is not in agreement with reality. When comparing the statistical significance between the absolute log power density spectra and those concerning relative power, some interesting differences appear. For the frequency range from 0.7 to $7.7 \mathrm{~Hz}$ in the derivations $\mathrm{P} 4-\mathrm{O} 2$ and T4-T6 the statistical significance of the HV effect appeared to be higher for the relative subtraction spectra than for the absolute subtraction spectra. The standard deviation among the subjects was reduced by the normalization by about $20 \%$, whereas the means did not differ much. For the derivation F4-C4 the opposite was true. Despite slightly increased variance for the absolute subtraction spectra, the large amount of the power increase led to about $40 \%$ higher ratios of mean to standard deviation.

Subtraction spectra of absolute log power density represent spectral changes more in agreement with reality than subtraction spectra of relative $\log$ power density. Spectral changes in the delta and theta bands due to $\mathrm{HV}$ were most pronounced in the derivation F4-C4 and increase in slow beta 
band was only present in this derivation. In addition, the statistical significance of the $\mathrm{HV}$ induced changes was greatest for this derivation. For these reasons, when studying the HV response in the derivation F4-C4 absolute log power densities should be selected. In contrast, when studying the derivations $\mathrm{P} 4-\mathrm{O} 2$, a preference should be given to relative $\log$ power densities, because of their better statistical significance and least contamination with artifacts.

\section{(2) The effect of standardized $H V$ on classical qEEG parameters}

Table III shows the effects of standardized HV on the selected classical relative qEEG parameters. Both mean differences and quotients of mean and group standard deviation are indicated. Relative power in the delta 1 and 2 bands as well as the mean frequency of the total spectrum and Hjorth's mobility show the most significant changes in the derivation P4-O2. This is in agreement with the subtraction spectra of relative log power density and with findings in a previous study of hypobaric hypoxia (Kraaier et al. 1988). This table shows that the derivation $\mathrm{P} 4-\mathrm{O} 2$ is preferable in the study of $\mathrm{HV}$-induced EEG changes with relative classical band parameters, because of the degree of significance of these effects. Absolute classical band parameters for the 3 derivations were less significant than the relative band power data. When considering classical band parameters the preference for absolute power estimates in the derivation F4-C4 as found for subtraction spectra was no longer present.

(3) Comparison of subtraction spectra and classical qEEG parameters during standardized $H V$ and hypobaric hypoxia

In a previous study (Kraaier et al. 1988) the relative qEEG effects of hypobaric hypoxia (atmospheric pressure decreased to $46.6 \mathrm{kp}_{\mathrm{a}}$; mean decrease in haemoglobin oxygen saturation to $70 \%$ ) were studied. Fig. 5 and Table IV show the subtraction spectra of relative $\log$ power density and classical qEEG parameters for the deviation $\mathrm{P} 4-\mathrm{O} 2$ in both studies. Clearly both the increase in slow activity as well as the decrease in alpha and beta activity are more pronounced in the HV model,

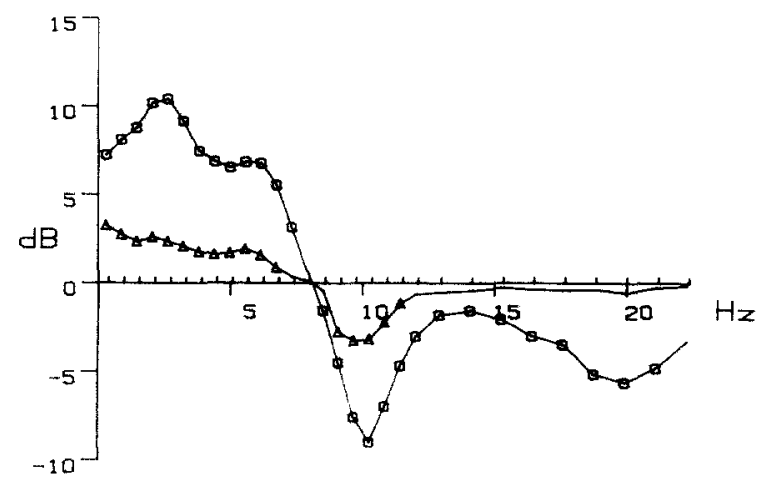

Fig. 5. Comparison of subtraction spectra of relative log power density during hypobaric hypoxia $(\mathrm{N}=21)$ and standardized hyperventilation $(N=24)$. $\square$ : hyperventilation; $\Delta$ : hypoxia. Symbols indicate a significant difference $(P<0.05)$.

whereas the general shapes of the curves are similar in the two studies.

\section{(4) Reproducibility}

When the HV procedure was repeated after $1 \mathrm{~h}$, in general the spectral effects appeared to be slightly smaller than in the first $\mathrm{HV}$ period. From a comparison in pairs of the changes in the first and second $\mathrm{HV}$ periods it followed that these differences were significant $(P<0.05)$ in the $2-7.5$ $\mathrm{Hz}, 10-11 \mathrm{~Hz}$ and $16-21 \mathrm{~Hz}$ range. At the start of the second $\mathrm{HV}$ procedure $\mathrm{pCO}_{2}$ appeared to be $4 \%$ below the initial baseline level. A similar decrease in BFV of 5\% was found as well. When the HV procedure was repeated after 1 week, no significant differences within the spectral changes were found.

\section{TABLE IV}

Comparison of mean changes (standard deviation) in relative band powers due to hypobaric hypoxia and standardized $\mathrm{HV}$. Derivation $\mathrm{P} 4-\mathrm{O} 2$.

\begin{tabular}{lcc}
\hline & $\begin{array}{l}\text { Hypobaric } \\
\text { hypoxia } \\
(\mathrm{N}=21)\end{array}$ & $\begin{array}{l}\text { Standardized } \\
\text { hyperventilation } \\
(\mathrm{N}=24)\end{array}$ \\
\hline Rel p delta 1 (\%) & $16.5(10.0)$ & $35.2(11.4)$ \\
Rel p delta 2 (\%) & $3.9(2.3)$ & $15.4(4.3)$ \\
Rel p theta (\%) & $3.4(2.3)$ & $7.9(9.6)$ \\
Rel p alpha 1 (\%) & $-14.1(14.8)$ & $-24.0(16.2)$ \\
Rel p alpha 2(\%) & $-8.4(8.5)$ & $-24.3(17.0)$ \\
Mean freq. tot. spec. $(\mathrm{Hz})$ & $-1.9(1.5)$ & $-5.4(3.2)$ \\
\hline
\end{tabular}




\section{Discussion}

\section{The HV model}

\section{Hyperventilation and $C B F / B F V$}

It has been recognized before (Lubin and Price 1942; Schieve and Wilson 1953; Swanson et al. 1958) that $\mathrm{CO}_{2}$ is an important regulator of the cerebral vasomotor apparatus. Depression of $\mathrm{pCO}_{2}$ causes vasoconstriction of the arteriolar channels, leading to an increase in the peripheral vascular resistance and a decrease of the CBF (Kety and Schmidt 1948; Wasserman and Patterson 1961). This increase of the peripheral vascular resistance is also responsible for the decrease of the BFV in the large cerebral arteries (Markwalder et al. 1984).

During the standardized HV procedure a decrease in BFV of the MCA to $40 \%$ of baseline values was demonstrated. This finding is in accordance with other TCD studies (Markwalder et al. 1984). The BFV findings in the present study are in agreement with a decrease to $30-40 \%$ of CBF in earlier studies (Kety and Schmidt 1948; Meyer and Gotoh 1960; Severinghaus and Lassen 1967; Lassen 1970). In patients, a CBF between 10 and $15 \mathrm{ml} / \mathrm{min} / 100 \mathrm{~g}$ was measured in the zone described as the ischaemic penumbra (Welch and Barkley 1986). Moreover, it has been demonstrated (Reivich 1964) that an HV-induced decrease of $\mathrm{pCO}_{2}$ to 15 torr $=2 \mathrm{kp}_{\mathrm{a}}$ gave rise to a decrease in CBF from 49.3 to $20.9 \mathrm{ml} / \mathrm{mg} / 100 \mathrm{~g}$. Thus, in the present study, the decrease in CBF approximates the values of the ischaemic penumbra (Astrup et al. 1981).

\section{Hyperventilation and cerebral hypoxia}

Whether the diminution in cerebral blood flow due to $\mathrm{HV}$ is large enough to cause cerebral hypoxia has been questioned by Mallette and Eiseman (1958), who argued that a great deal of cerebral hypoxia is caused by the Bohr effect (Bohr et al. 1904), with its shift of the oxygen dissociation curve to the left due to respiratory alkalosis. Polarographic determinations have demonstrated a decrease in cerebral surface $\mathrm{pO}_{2}$ during hyperventilation in dogs and cats (Clark et al. 1958; Sugioka and Davis 1960; Adams and Severinghaus 1962). It has, however, been dis- puted whether surface $\mathrm{pO}_{2}$ reflects deep tissue $\mathrm{pO}_{2}$ (Laux and Raichle 1978).

Mass spectrometric studies have demonstrated the effect of HV upon deep cerebral tissue oxygen and carbon dioxide tensions in dogs (Kennealy et al. 1980): acute hypocapnic hyperventilation was associated with a significant decrease in cerebral tissue $\mathrm{pO}_{2}$. Furthermore, in animal and human studies a significant increase in cerebral lactate has been measured during HV (Plum and Posner 1967; Luyten et al. 1987).

In conclusion, it can be stated that hyperventilation gives rise to a combination of decreased CBF, cerebral tissue hypoxia and lactacidosis. These effects occur also in cerebral ischaemia and the differences between $\mathrm{HV}$ effects and ischaemia effects are more a matter of extent than of essence.

\section{Age dependency}

Yamaguchi et al. (1979) demonstrated that normally advancing age decreases the cerebral vasoconstrictive response during HV. This is explained by the lower $\mathrm{CBF}$ in older persons at rest, while the $\mathrm{CBF}$ during maximal $\mathrm{HV}$ is equal for all ages. Thus, the relative decrease in CBF during $\mathrm{HV}$ is greatest in younger subjects. Both at rest and during standardized $\mathrm{HV}$ a sex difference for TCD values has been found (Vriens et al. 1987). To standardize the age and sex related vasoconstrictive response, only young male subjects in a small age range have been studied.

\section{Capnography}

The primary effect of $\mathrm{HV}$ is a significant decrease in alveolar $\mathrm{pCO}_{2}$ as well as arterial $\mathrm{pCO}_{2}$, which are always in equilibrium. End-tidal $\mathrm{pCO}_{2}$ values approximate those of alveolar $\mathrm{pCO}_{2}$ (Dubois et al. 1952) and are only slightly larger than those of arterial estimates (Saxton 1953). For these reasons infra-red $\mathrm{pCO}_{2}$ analysis, allowing effortless and continuous monitoring of the endtidal $\mathrm{pCO}_{2}$ throughout the period of overbreathing, is admirably suitable. It permits a control on individual performance, rendering it consistent and reproducible. Monitoring the capnogram and encouraging the subjects to take deep breaths prevented dead space ventilation, in which case the 
arterial $\mathrm{pCO}_{2}$ would be higher than the end-tidal $\mathrm{pCO}_{2}$. An end-tidal $\mathrm{pCO}_{2}$ of $2 \mathrm{kp}_{\mathrm{a}}$ was chosen for $\mathrm{HV}$, because it caused considerable and homogenous changes in the BFV of young subjects (Vriens et al. 1987) and because it is the lowest degree that most subjects are able to maintain rather effortlessly throughout the HV procedure. In general, voluntary hyperventilation does not lower the alveolar $\mathrm{pCO}_{2}$ below $2 \mathrm{kp}_{\mathrm{a}}$, because the 'exercise' of hyperventilation itself causes an increase in $\mathrm{CO}_{2}$ metabolically produced (Samson Wright 1971).

\section{Heart rate}

The mean heart rate showed an increase to $158 \%$ of baseline value during standardised $\mathrm{HV}$. This finding is in accordance with other studies (Holmberg 1953; Gotoh et al. 1965; Stoddart 1967; Kennealy et al. 1986). The rise in heart rate has been attributed to muscular exercise involved in overbreathing (Proger and Ayman 1933) but this was refuted in later studies (Thompson et al. 1962). In fact, the precise mechanism of the increase in heart rate during $\mathrm{HV}$ is not known (Zwillich et al. 1976).

\section{Blood pressure}

Blood pressure, both systolic and diastolic, did not alter during standardised HV. In the classical report of Kety and Schmidt (1948) blood pressure showed a tendency to rise during HV, while some years earlier (Darrow and Pathman 1943) a tendency to decrease was observed.

\section{The EEG response to $H V$}

An increase in slow activity and a decrease in alpha activity during HV were observed in spontaneous EEG from the beginning of electroencephalography (Berger 1934; Davis and Wallace 1942; Gibbs et al. 1942). Only recently has spectral analysis of the EEG been performed during hyperventilation, with decreasing end-tidal $\mathrm{pCO}_{2}$ to a level of 21 torr (Kennealy et al. 1986). An increase in total amplitude and percentage delta activity $(0.50-3.99 \mathrm{~Hz})$ was found as well as a decrease in the 25 th percentile frequency, percentage alpha activity $(8-11.99 \mathrm{~Hz})$ and the peak frequency of the entire spectrum. These findings are in agreement with the results of this study. However, in the present study the volunteers reached a lower end-tidal $\mathrm{pCO}_{2}\left(15\right.$ torr $\left.=2 \mathrm{kp}_{\mathrm{a}}\right)$, leading to more impressive qEEG changes. Furthermore, in the present study BFV was measured as well and the reproducibility for a set of 13 qEEG parameters (Table I) was analysed for 3 derivations.

\section{Classical band parameters}

In most studies of qEEG changes due to ischaemia (Van Huffelen et al. 1984) relative classical band parameters have been calculated, reducing the large inter-individual variance. A disadvantage of band parameters is the limited possibility to detect small effects on the crossing of bands. This study demonstrates once more that relative classical band parameters from the derivation P4-O2 should be selected when, for statistical reasons, reliable data with a small variance are preferred. In the standardized HV model the inter-subject variance was reduced to such a degree that calculation of absolute power densities still resulted in homogenous effects. Nevertheless, data from absolute classical band parameters for the 3 derivations were less significant than the relative band power data.

\section{Subtraction spectra}

In clinical conditions, the EEG spectrum of the ischaemic hemisphere is compared with the EEG spectrum of the non-affected side, in order to detect even subtle intra-individual differences ( $V$ an Huffelen et al. 1980). In this study, for the same reason, the EEG spectra during HV were compared with baseline spectra. Calculation of subtraction spectra is more complex than of classical parameters. A major advantage of this method is the more realistic presentation of the EEG changes. Once again, the present study showed that the derivation $\mathrm{P} 4-\mathrm{O} 2$ should be selected when studying subtraction spectra of relative band power, because of its largest statistical significance and least contamination with artifacts. A disadvantage of relative qEEG parameters is the fact that changes in one frequency range are influenced by changes in another frequency range. In the stan- 
dardized HV model subtraction spectra of absolute bandpower showed spectral changes that were in contrast with relative subtraction spectra. In the derivation F4-C4, using absolute power estimates, slow beta activity actually showed an increase during HV. Moreover, it became apparent that spectral changes and their statistical significance were most prominent when studying the derivation F4-C4. For these reasons, when studying absolute subtraction spectra the derivation F4-C4 should be selected. It may be concluded that in any study of qEEG changes, the selection of parameters and derivations is rather complex and that the preference for absolute or relative power data is dependent on the magnitude of the effect and the inter-individual variance. The present study has shown that there is a mutual dependency of all these variables.

\section{Hypoxia and ischaemia}

Three types of hypoxia may be distinguished (Plum and Posner 1967), i.e., hypoxic, anaemic and ischaemic. In hypoxic hypoxia the oxygen supply to the blood is insufficient. In an earlier study, this was achieved in a low pressure chamber (Kraaier et al. 1988). In ischaemic hypoxia the blood may carry sufficient oxygen, but the cerebral blood flow is insufficient. Ischaemic hypoxia is generally more dangerous than hypoxic hypoxia, because not only oxygen, but also glucose is supplied insufficiently and because potentially toxic products of cerebral metabolism, such as lactic acid and short chain fatty acids are not removed. EEG changes due to ischaemic hypoxia have the same characteristics and may even be identical to EEG changes due to hypoxic hypoxia (Gibbs et al. 1935; Meyer and Gotoh 1960).

In a previous study (Kraaier et al. 1988) 21 subjects were exposed to hypobaric hypoxia (atmospheric pressure $46.5 \mathrm{kp}_{\mathrm{a}}$ ) during $19 \mathrm{~min}$. Fig. 5 and Table IV show that the qEEG changes in both studies have the same characteristics, but are far more outspoken in the HV model.

\section{Reproducibility}

The reproducibility of the qEEG changes with a $1 \mathrm{~h}$ interval appeared to be incomplete, showing especially a lesser increase of slow activity in the second procedure. A $1 \mathrm{~h}$ interval was apparently too short to restore the normal physiological conditions, as was observed in the $4-5 \%$ lower baseline values of $\mathrm{BFV}$ and $\mathrm{pCO}_{2}$. In an earlier study (Davis and Wallace 1942) even a $1.75 \mathrm{~h}$ interval after HV appeared to be too short to obtain reproducible changes in EEG. In this study the reproducibility of the qEEG changes with a 1-week interval appeared to be good.

\section{Application}

In normal young subjects the standardized $\mathrm{HV}$ model might be used to test the efficacy of antihypoxic, anti-ischaemic or vaso-active drugs. In the presented procedure, the neuronal effects are measured by qEEG analysis, while the BFV is recorded by the TCD technique. Combining these measurements, a differentiation might be obtained between a neuronal and a vascular effect of an experimental drug. The standardized HV procedure in young human subjects appears to be a harmless, easily applicable and reproducible model for studying ischaemic changes. In patients, the standardized HV procedure could be used to evaluate the functional integrity and reactivity of the cerebrovascular system.

The authors wish to thank Ms. Cora Van den Berg for preparing the manuscript.

\section{References}

Aaslid, R., Markwalder, T.M. and Normes, H. Noninvasive transcranial Doppler ultrasound recording of flow velocities in basal cerebral arteries. J. Neurosurg., 1982, 57: 769-774.

Adams, J.E. and Severinghaus, J.W. Oxygen tension of human cerebral grey and white matter. The effect of forced hyperventilation. J. Neurosurg., 1962, 19: 959-963.

Astrup, J., Siesjö, B.K. and Symon, L. Thresholds in cerebral ischemia - the ischemic penumbra. Stroke, 1981, 12 723-725.

Berger, $H$. On the electroencephalogram of man. 9th report. Arch. Psychiat. Nervenkr., 1934, 102: 538-557. Translated by C. Gloor in Hans Berger 'On the EEG of Man.' Electroenceph. clin. Neurophysiol., 1969, Suppl. 28: $225-242$.

Bohr, C., Hasselbach, K.A. und Drough, A. Ueber einen in 
biologischer Beziehung wichtigen Einfluss den die Kohlensäurespannung des Blutes auf dessen Sauerstoffbindung übt. Scand. Arch. Physiol., 1904, 16: 402-412.

Clark, L.C., Misraki, G.A. and Fox, R.P. Studies with Chronically Implanted Polarographic Electrodes. A.A.D.C. Techn. Rep. 57, 570. Fasc. Carpenter, Springfield, IL, 1958: 21 pp.

Darrow, C.W. and Pathman, J.H. The role of blood pressure in EEG changes during hyperventilation. Fed. Proc., 1943, 2: 9.

Davis, H. and Wallace, W. Factors affecting changes produced in electroencephalogram by standardized hyperventilation. Arch. Neurol. Psychiat., 1942, 47: 606-625.

Dubois, A.B., Fowler, R.C., Soffer, A. and Fenn, W.O. Alveolar $\mathrm{CO}_{2}$ measured expiration into rapid infra-red gasanalyser. J. Appl. Physiol., 1952, 4: 526-534.

Gibbs, E.L., Gibbs, F.A., Lennox, W.G. and Nims, L.F. Regulation of cerebral carbon dioxide. Arch. Neurol. Psychiat., 1942, 47: 879-889.

Gibbs, F.A., Davis, H. and Lennox, W.G. The electroencephalogram in epilepsy and in condition of impaired consciousness. Arch. Neurol. Psychiat., 1935, 34: 1133-1148.

Gotoh, F., Meyer, J.S. and Takagi, Y. Cerebral effects of hyperventilation in man. Arch. Neurol., 1965, 12: 410-423.

Hauge, A., Thoresen, M. and Walloe, I. Changes in cerebral blood flow during hyperventilation and $\mathrm{CO}_{2}$-breathing measured transcutaneously in humans by a bidirectional pulsed ultrasound Doppler blood velocity meter. Acta Physiol. Scand., 1980, 110: 167-173.

Hjorth, B. EEG analysis based on time domain properties. Electroenceph. clin. Neurophysiol., 1970, 29: 306-310.

Hjorth, B. The physical significance of time domain descriptors in EEG analysis. Electroenceph. clin. Neurophysiol., 1973, 34: $321-325$

Holmberg, C. The EEG during hypoxia and hyperventilation. Electroenceph. clin. Neurophysiol., 1953, 5: 371

Kennealy, J.A., McLennan, J.E., Loudon, R.G. and McLaurin, R.L. Hyperventilation induced cerebral hypoxia. Am. Rev. Resp. Dis., 1980, 122: 407-412.

Kennealy, J.A., Penovich. P.E. and Moore-Nease, S.E. EEG and spectral analysis in acute hyperventilation. Electroenceph. clin. Neurophysiol., 1986, 63: 98-106.

Keskimäki, I. et al. Electroenceph. clin. Neurophysiol., 1980 , 50: 496-501.

Kety, S.S. and Schmidt, C.F. Effects of altered arterial tensions of carbon dioxide and oxygen on cerebral blood flow and cerebral oxygen consumption of normal young men. $J$. Clin. Invest., 1948, 27: 484-492.

Kogure. K., Busto, R., Natsumoto, A., Scheinberg, P. and Reinmuth, O.M. Effects of hyperventilation on dynamics of cerebral energy metabolism. Am. J. Physiol., 1975. 228: 1862-1867.

Kraaier, V., Van Huffelen, A.C. and Wieneke, G.H. Quantitative EEG changes due to hypobaric hypoxia in normal subjects. Electroenceph. clin. Neurophysiol., 1988, 69 : 303-312.

Laux. B.E. and Raichle, M.E. The effect of acetazolamide on cerebral blood flow and oxygen utilization in the rhesus monkey. J. Clin. Invest., 1978, 38: 585-592.

Lubin, A.J. and Price, J.C. Effects of alkalosis and acidosis on cortical electrical activity. J. Neurophysiol., 1942, 5 : 261-268.

Luyten, P.R., Van Rijen, P.C., Berkelbach van de Sprenkel. J.W., Tulleken, C.A.F., Wieland, J. and Den Hollander, J.A. ${ }^{1} \mathrm{H}$ and ${ }^{31} \mathrm{P}$ NMR measurements of cerebral lactate levels and $\mathrm{pH}$ in humans during hyperventilation. In: Sixth Annual Meeting, New York Hilton Hotel, NY, U.S.A Society of magnetic resonance in medicine. August $17-21$. 1987.

Malette, W.G. and Eiseman, B. Cerebral anoxia resulting from hyperventilation. Surg. Forum, 1958, 10: 208.

Markwalder, T.M., Grolimund, P., Seiler, R.W., Roth, F. and Aaslid, R. Dependency of blood flow velocity in the middle cerebral artery on end-tidal carbon dioxide partial pressure. A transcranial ultrasound Doppler study. J. Cereb. Blood Flow Metab., 1984, 4: 368-372.

Meyer, J.S. and Gotoh, F. Metabolic and electroencephalographic effects of hyperventilation. Arch. Neurol., 1960, 5 : 539-552.

Plum, F. and Posner, J.B. Blood and cerebrospinal fluid lactate during hyperventilation. Am. J. Physiol., 1967, 212: $864-870$.

Proger, S.H. and Ayman, D. Hyperventilation in arteriolas hypertension. J. Clin. Invest.. 1933, 12: 335

Reivich, M. Arterial pCO, and cerebral hemodynamics. Am. J. Physiol., 1964, 206: 25 - 35.

Samson Wright's Applied Physiology, 12th edition. University Press. London, 1971

Saxton, G.A. Method for sampling and analysing alveolar $\mathrm{pCO}_{2}$. Fed. Proc., 1953. 12: 125.

Schieve, J.F. and Wilson, W.P. The changes in cerebral vascular resistance of man in experimental alkalosis and acidosis J. Clin. Invest., 1953, 32:33.

Severinghaus, J.W. and Lassen. N. Step hypocapnia to separate arterial from tissue $\mathrm{pCO}_{2}$ in the regulation of cerebral blood flow. Circulat. Res., 1967, 20: 272-278.

Stoddart, J.C. Electroencephalographic activity during voluntarily controlled alveolar hyperventilation. Br. J. Anaesth., 1967, 39: 2-10.

Sugioka, K. and Davis. D.A. Hyperventilation with oxygen, a possible cause of cerebral hypoxia. Anesthesiology. 1960 , 21: $135-143$

Swanson, A.G., Stavney, L.S. and Plum, F. Effects of blood $\mathrm{pH}$ and carbon dioxide on cerebral electrical activity. Neurology, 1958, 8: 787-792.

Thompson, H.K., Berry, J.N. and McIntosh, H.D. Circulatory responses to hyperventilation and exercise in normal subjects. Am. Heart J., 1962, 63: 106-114.

Van Huffelen, A.C., Poortvliet, D.C.J., Van der Wulp, C.J.M. and Magnus, O. Quantitative EEG in cerebral ischemia. In: H. Lechner and A. Aranibar (Eds.), EEG and Clinical Neurophysiology. Proc, 2nd European Congress of EEG and Clinical Neurophysiology. Excerpta Medica, Amsterdam, 1980: 125--137

Van Huffelen, A.C., Poortvliet, D.C.J. and Van der Wulp. C.J.M. Quantitative electroencephalography in cerebral ischemia. Detection of abnormalities in 'normal' EEGs. In: G. Pfurtscheller, E.J. Jonkman and F.H. Lopes da Silva (Eds.), Brain Ischemia: Quantitative EEG and Imaging 
Techniques. Progress in Brain Research, Vol. 62. Elsevier, Amsterdam, 1984: 3-29.

Vriens, E.. Kraaier, V. and Musbach, M. Hyperventilation (HV)-induced changes of blood flow velocity (BFV) in the middle cerebral artery (MCA) in relation to age and sex. Transcranial pulsed Doppler ultrasound (TDPU) measurements at rest and during controlled HV. Clin. Neurol. Neurosurg., 1987, 89 (Suppl. I): 149.

Wasserman, A.J. and Patterson, J.L. The cerebral vascular response to reduction in arterial carbon dioxide tension. $\mathrm{J}$. Clin. Invest., 1961, 40: 1297-1303.

Welch, K.M.A. and Barkley, G.L. Biochemistry and pharmacology of cerebral ischemia. In: H.J.M. Barnett, B.M.
Stein, J.P. Mohr and F.M. Yatsu (Eds.), Stroke, Pathophysiology, Diagnosis and Management, Vol. 1. Churchill Livingstone, New York, 1986: 75-90.

Wieneke, G.H., Deinema, C.H.A., Spoelstra, P., Storm van Leeuwen, W. and Versteeg, H. Normative spectral data on alpha rhythm in male adults. Electroenceph. clin. Neurophysiol., 1980, 49: 636-645.

Yamaguchi, F., Meyer, J.S., Sakai, F. and Yamamoto, M. Normal human aging and cerebral vasoconstrictive responses to hypocapnia. J. Neurol. Sci., 1979, 44: 87-94.

Zwillich, C.W., Pierson, D.J., Creach, E.M. and Weil, J.V. Effects of hypocapnia and hypocapnic alkalosis on cardiovascular function. J. Appl. Physiol., 1976, 40: 333-337. 